\title{
Correlação Clínico-Radiográfica \\ Caso 6/2004 - Instituto do Coração do Hospital das Clínicas da FMUSP
}

\author{
Edmar Atik
}

São Paulo, SP

Dados clínicos - Em lactente com 14 meses de idade, sexo masculino e de cor branca, sopro cardíaco, foi auscultado de rotina com 30 dias de vida. 0 diagnóstico inicial foi de comunicação interventricular de moderada repercussão por características do sopro sistólico, acompanhado de frêmito, sobrecarga biventricular no eletrocardiograma e trama vascular pulmonar e área cardíaca aumentadas na radiografia de tórax. Na evolução com 6 meses de idade, o desaparecimento do frêmito e a sobrecarga ventricular direita no eletrocardiograma orientaram ao diagnóstico de estenose pulmonar infundibular associada. Cianose ao choro com 8 meses, progressiva até 14 meses, crise de hipóxia e irritabilidade motivaram à indicação operatória corretiva. Ao exame físico apresentavase em bom estado geral, cianótico ++, eupnéico e com pulsos normais. A pressão arterial era de $90 / 60 \mathrm{mmHg}$, a freqüência cardíaca de $120 \mathrm{bpm}$, o peso de 8,6 kg, a altura de $73,5 \mathrm{~cm}$ e a saturação de oxigênio $70 \%$. A aorta não foi palpada na fúrcula. No precórdio não havia deformidades ou impulsões e o ictus cordis não foi palpado. As bulhas eram hiperfonéticas sendo a $2^{\mathrm{a}}$ bulha mais acentuada na área tricúspide que pulmonar. Havia sopro sistólico $+/++$, de ejeção, suave, no $3^{\circ}, 2^{\circ}$ e $4^{\circ}$ espaços intercostais esquerdos. 0 fígado não foi palpado.

0 eletrocardiograma mostrou ritmo sinusal e sinais de sobrecarga ventricular direita com onda R em V1 de $23 \mathrm{~mm}$ e complexo rS em V6. A onda T era positiva em V1, mas menos positiva que em V6. A onda $P$ tinha $3 \mathrm{~mm}$ de amplitude em D2, indicativa de sobrecarga atrial direita. SÂP: $+60^{\circ}$, SÂQRS: $+140^{\circ}$, SÂT: $+50^{\circ}$.

Imagem radiográfica - Mostra área cardíaca normal com ponta cardíaca elevada, arco médio escavado, arco aórtico à direita e trama vascular pulmonar algo aumentada nas regiões hilares diminuindo na periferia, até para os lobos inferiores (fig.1).

Impressão diagnóstica - Esta imagem orienta para o diagnóstico da tetralogia de Fallot, dada a morfologia cardíaca característica, ainda mais apresentando 0 arco aórtico desviado à direita e com o arco médio escavado. A trama pulmonar aumentada pode corresponder à presença de situação hemodinâmica prévia de hiperfluxo pulmonar, antes do agravamento da estenose pulmonar infundibular.

Diagnóstico diferencial - Associação da tetralogia de Fallot com outras anomalias que aumentam o fluxo pulmonar devem ser lembra-

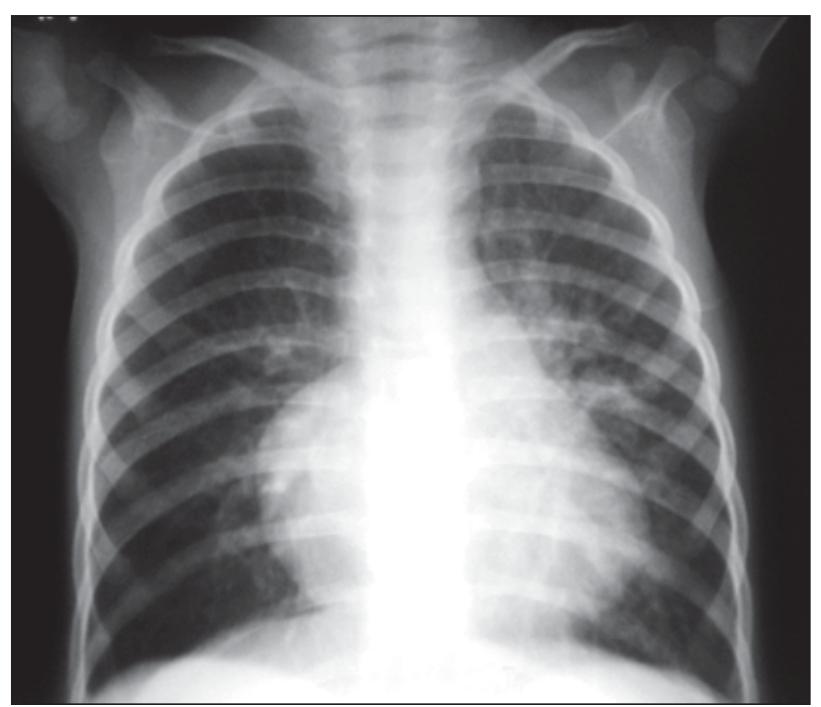

Fig. 1-Radiografia de tórax mostra a forma característica da encontrada na tetralogia de Fallot mas com acentuação da trama vascular pulmonar nas regiões hilares.

das como a agenesia valvar pulmonar, vasos colaterais sistêmicopulmonares ou mesmo o canal arterial. Ainda mais, outras anomalias que se acompanhem da comunicação interventricular e da estenose pulmonar como na atresia tricúspide, ventrículo único, atresia pulmonar, atresia mitral, devem também ser lembradas.

Confirmação diagnóstica - Os elementos clínicos eram característicos para, facilmente, se estabelecer o diagnóstico da tetralogia de Fallot. 0 ecocardiograma mostrou os elementos que caracterizam o diagnóstico, como a comunicação interventricular perimembranosa, a estenose pulmonar infundibular por desvio do septo infundibular e a dextroposição da aorta cavalgando o septo ventricular. As artérias pulmonares tinham diâmetros de $8 \mathrm{~mm}$. 0 cateterismo cardíaco mostrou pressões sistêmicas em ventrículo direito, discreta dextroposição da aorta, estenose pulmonar infundibular acentuada e artérias pulmonares de bom calibre. A aorta dilatada tinha arco à direita.

Conduta - À operação, o anel pulmonar era bom e não foi ampliado. A estenose infundibular foi ressecada e a comunicação interventricular fechada com boa evolução clínica. Não houve demonstração posterior de defeitos residuais. 